\title{
SHORT FATIGUE CRACK GROWTH IN A RESIDUAL STRESS FIELD IN A 7075 AL-ALLOY AFTER SHOT PEENING
}

The paper contains results of an investigation of effects of shot peening on growth of physically short fatigue cracks in a $2.4 \mathrm{~mm}$ thick sheet of an aircraft V-95 Al-alloy (a type of a 7075 alloy), clad with a 7072 Al-alloy (Al-Zn1). Using an improved and verified experimental methodology, particularly direct current potential drop (DCPD) method, short fatigue cracks of the length from $0.2 \mathrm{~mm}$ to more than $3 \mathrm{~mm}$, most of them between $0.8-1.5 \mathrm{~mm}$, were prepared under high cycle fatigue repeated tensile loading of the constant nominal stress range 160 $M P a$, load asymmetry $R=0$. Edges of the specimens with already existing short fatigue cracks were then shot peened using two different groups of parameters. Some reference specimens without cracks were shot peened with the same parameters. Microhardness measurement and informative measurement of residual stresses near the peened edges were carried out. Significant retardation of crack growth was observed particularly in case of cracks shorter than $2 \mathrm{~mm}$. The work was completed by a unique measurement of actual crack growth rate throughout the peened area with residual stresses starting with crack length less than $0.2 \mathrm{~mm}$. Different stages of the growth are discussed.

Keywords: Fatigue crack growth, short cracks, shot peening, residual stresses, 7075 Al-alloy

\section{Introduction}

Shot peening is one of surface treatment methods applied to various metallic materials either separately or in a combination with other surface treatments like plating, hard anodising etc., in order to locally improve the performance of mechanical components under fatigue loads $[1,2]$. This treatment creates compressive residual stresses that usually increase the operating life of the component. In order to perform an effective and reliable design, it is not namely adequate to consider only the in-service stress of the component. Unforeseen cracks can occur due to the fact that tensile residual stresses added to the in-service stress decrease the component life. On the contrary, a strong improvement can be achieved, if compressive residual stresses are induced in the components.

The final effect of shot peening on fatigue resistance depends on numerous parameters and material which the technology is applied to $[3,4]$. If the technology parameters are not optimised for a specific material and for its basic structural and mechanical properties, shot peening may not be beneficial, fatigue resistance can even be deteriorated [5, 6]. Recent advanced approaches are based on the hypothesis that compressive residual stresses are able to slow down or stop crack propagation instead of preventing their initiation, and, therefore, they are based on main concepts of fracture mechanics. This approach is conditioned by the use of sophisticated experimental methods, particularly preparation of physically short fatigue cracks in specimens of reasonable dimensions suitable for shot peening applications and exact measurement of actual crack length including not only surface path but also an estimation of crack profile inside the specimen. Length of short cracks is usually measured optically (e.g. [7]), which however does not enable to assess the subsurface length. Complex crack growth measurement including subsurface profile, which is an essential condition of application of fracture mechanics approaches, is not an easy task, particularly if specimens are of quite big dimensions.

In the paper, results and analyses of an extensive experimental programme aimed at an evaluation of effects of shot peening applied to clad V-95 Al-alloy (7075 Al-alloy) sheets on growth and retardation of existing short fatigue cracks are presented and discussed.

\section{Experimental material}

The work was addressed to potential use in aircraft industry with the aim to investigate conditions of retardation of short or physically small cracks or crack-like defects using shot peening. Therefore, a V-95 Al-alloy, clad with Al-Zn1 (7072 Al-alloy) surface layers was selected as the experimental material.

The V-95 material is a Russian Al-alloy of Al-Zn-Mg type and due to its high mechanical properties and fatigue resistance, it has been widely used for aircraft structures, such as wings and fuselages, already for many years [8]. According to Russian GOST standard, the typical chemical contents of $\mathrm{Zn}$ is $5-7$ weight $\%, \mathrm{Mg}$ 2-3\%, $\mathrm{Cu}$ approximately $1.5 \%$ and $\mathrm{Mn} 0.35-0.6 \%$, whereas chemical composition affects quite strongly the material harden-

\footnotetext{
* Ivo Cerny, Dagmar Mikulova, Jiri Sis

SVUM a.s., Praha, Czech Republic, E-mail: Ivo.Cerny@seznam.cz
} 
ability [9]. A similar US type of the material is represented by a 7075 Al-alloy with just slightly lower content of $\mathrm{Zn}$ and $\mathrm{Cu}$. Typical values of basic mechanical properties of this material at heat-treated conditions are: strength up to $550 \mathrm{MPa}$ and yield stress up to $480 \mathrm{MPa}$.

The V-95 alloy was available in the form of sheets of the total thickness $2.4 \mathrm{~mm}$ including both cladding layers (both surfaces) of the thickness $0.07 \mathrm{~mm}$ each in Aeronautical Research and Test Institute in Prague, where specimens also were manufactured.

\section{Experimental programme}

The experimental programme contained the following steps:

- preparation of series of a sufficient, representative number of specimens with physically short fatigue cracks of different lengths from $0.35 \mathrm{~mm}$ to $3.6 \mathrm{~mm}$,

- shot peening of the specimens with short cracks, using two groups of parameters,

- characterisation of bulk material and shot peened layers in terms of deformation of the microstructure, microhardness and informative assessment of residual stresses,

- evluation of residual fatigue life of the shot peened specimens with pre-existing short fatigue cracks,

- evalution of fatigue life of specimens with no pre-cracking, both shot peened and without peening and, eventually,

- evaluation of actual growth rate of a short crack growing throughout the peened area with residual stresses.

The specimens were of quite big dimensions given by material availability, namely material sheets of the thickness $2.4 \mathrm{~mm}$, and technological reasons of the shot peening application. Flat specimens of the total thickness $2.4 \mathrm{~mm}$, total length $200 \mathrm{~mm}$ and basic width at gripping area $48 \mathrm{~mm}$ were manufactured. To localise the area of crack initiation and to enable subsequent shot peening of specimen edges, shallow necking was made from both the specimen sides. The necking radius was $28 \mathrm{~mm}$; the minimum width at the specimen centre was $24 \mathrm{~mm}$.

Using the adapted and verified methodology of short crack measurement by DCPD method, described in [10-13], fatigue cracks of different length between $0.35 \mathrm{~mm}$ and $3.6 \mathrm{~mm}$ were prepared in 17 specimens, whereas the length of most of the cracks was between $0.87 \mathrm{~mm}$ and $1.49 \mathrm{~mm}$ ( 9 specimens). The work programme was performed on the resonance SCHENCK PVQA machine. The loading was of sinusoidal repeated type (load asymmetry $R=0$ ) of the constant nominal stress range $160 \mathrm{MPa}$, load frequency around $17 \mathrm{~Hz}$. These load conditions were uniform for all the specimens. Artificial microscopic notches of dimensions less than $0.05 \mathrm{~mm}$ were made on the specimen edges to accelerate the microscopic crack initiation period.

After pre-cracking, the specimens were divided into two groups, each of them containing a similar spectrum of cracks lengths so that the groups could be compared to each other. Shot peening of two different parameters was applied at Technometra Radotín a.s. to the first and second group, respectively. Parameters of the shot peening were: Shot sizes $0.43-0.7 \mathrm{~mm}$ and $0.21-0.32 \mathrm{~mm}$ for the first group and second group, respectively, Almen intensity $A=0.25$ and $A=0.14$ for the first and second group respectively. Shot peening angle was $60^{\circ}$ and coverage $200 \%$ for both the groups. Both edges in the central area of specimens were shot peened from both sides to the distance of $4-4.5 \mathrm{~mm}$ or so from the edge. Shot peening area can be seen in Figs. 1 and 2.

The shot peened layers were characterised using metallographic analysis with an optical microscope Neophot 32 with a digital image processing, microhardness measurement using Hanemann device and informative measurement of residual stresses performed on the basis of a gradual measurement of strain changes with a Hottinger Baldwin Messtechnik strain gauge unit HBM UPM 60 during a gradual grinding material layers off.

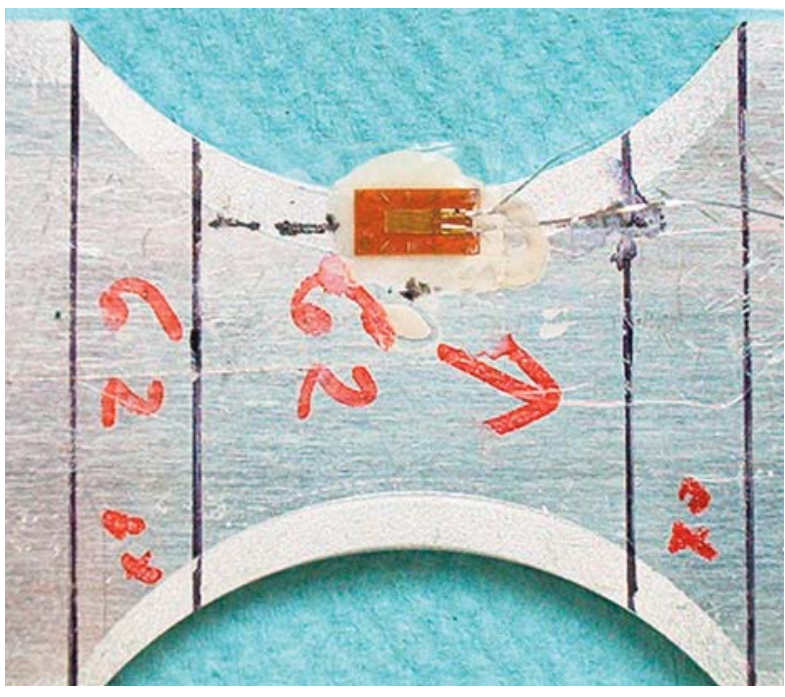

Fig. 1 Position of strain gauge at the centre of specimen with more severe shot peening

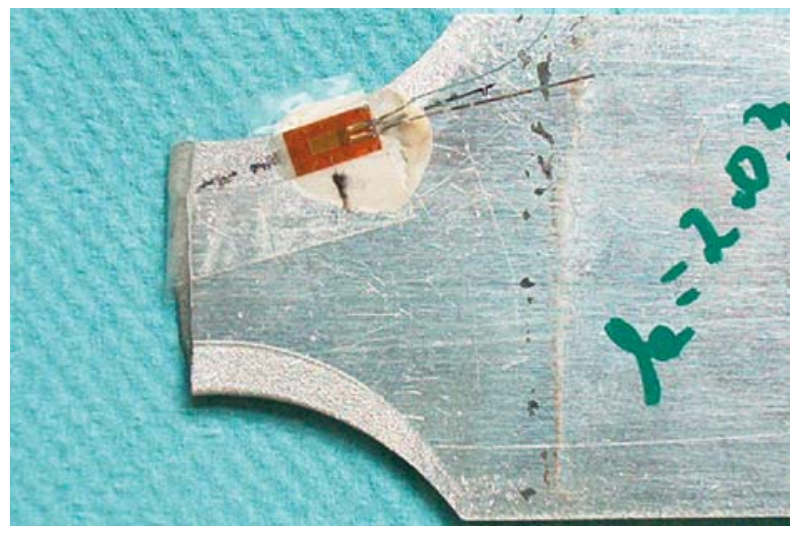

Fig. 1 Inclined position of strain gauge outside the centre of specimen with less severe shot peening 
The microhardness measurement HV 0.04 was performed in cross sections of two selected specimens treated with the two different peening parameters in the following areas: (i) near the shot peened clad specimen surfaces, i.e. at four different areas near each of the shot peened bands, (ii) near both the specimen edges where the cladding layer was absent and (iii) near the untreated clad surface for a comparison.

The method of assessment of the residual stress has to be described more in detail. Two specimens representing the two groups of shot peening parameters were equipped with a single strain gauge glued either in the centre of the shot peened area in the longitudinal direction - Fig. 1 (specimen with less severe peening parameters) or near the specimen centre in the inclined angle - Fig. 2 (more severe parameters), since no uncracked specimen was available in the latter case. After connecting the strain gauge device, the strain value was set to zero. The opposite surface of the specimen, which also contained the shot peened area, was then gradually ground off with steps of approximately $0.2 \mathrm{~mm}$ followed by strain recording. The remaining thickness of the material at the last step only was about $0.15 \mathrm{~mm}$. It could be therefore anticipated that original surface stresses were almost completely released and the final measured strain corresponded to this relaxation. It should be noted that the complex residual stress state near the edge, which was shot peened at both surfaces, was very complicated. Therefore, using the described simplified strain measurement, it could be assessed just informatively. However, the measurement provided at least some qualitative and partially quantitative results in terms of longitudinal residual stresses, most important from the viewpoint of fatigue crack initiation and early stages of growth.

Residual fatigue life of specimens containing the physically short fatigue cracks after shot peening was evaluated using the same loading conditions as those used for the precracking. Eventually, a sophisticated measurement of actual short crack growth throughout the shot peened area from its beginning was carried out.

\section{Results and discussion}

Microstructure analyses were carried out particularly in order to characterize the surface layers after shot peening. As expected, the shot peening effect on local surface and subsurface microstructure deformation was stronger for the first group of parameters, i.e. higher Balottini sizes and higher Almen intensity. A boundary area between shot peened and untreated surface is shown in specimen cross section in Fig. 3. It is evident that particularly the cladding layer was strongly deformed and compacted by the peening, resulting in numerous microscopic dimples, pits and also microcracks. On the other hand, it looks that the kinetic energy of the Balottini particles was accumulated through the plastic deformation in the cladding layer - no deformation of the microstructure under the layer was observed either in case of more severe or less severe peening. Some deformation of grains of the basic material, just slight, was observed just near the edges where cladding layer was absent - Fig. 4.

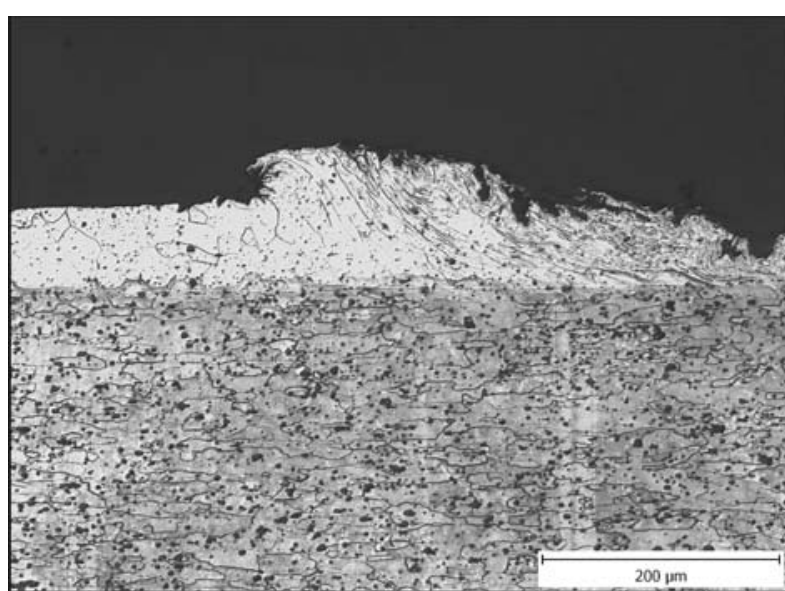

Fig. 3 Microstructure near boundary area between shot peened and untreated surface, more severe peening

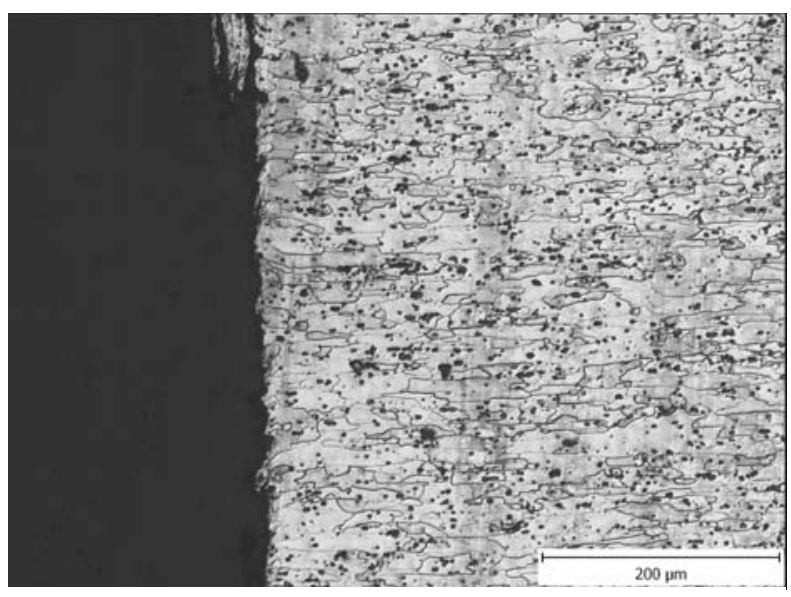

Fig. 4 Slight deformation of grains near the specimen edge, more severe peening

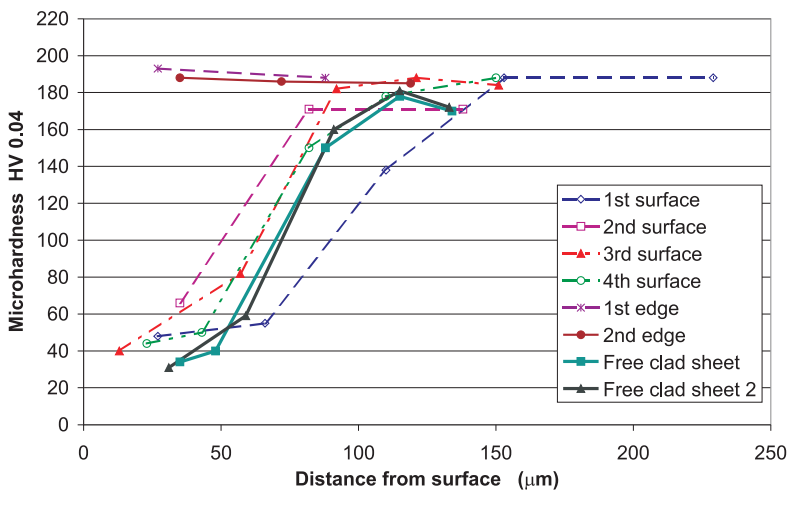

Fig. 5 Dependencies of microhardness on depth in specimen peened with more severe parameters 


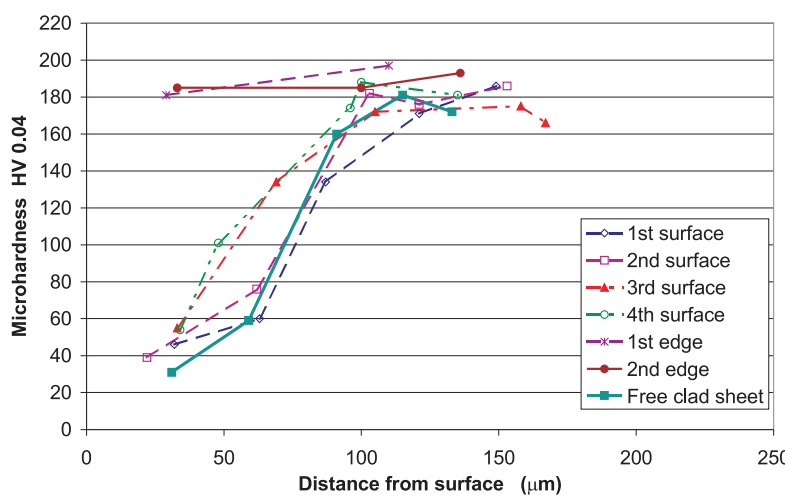

Fig. 6 Dependencies of microhardness on depth in specimen peened with less severe parameters

Results of microhardness measurement in specimens treated with the more and less severe parameters are shown in Figs. 5 and 6 , respectively. The fact that there is no distinct surface or subsurface hardening caused by the shot peening, either near the clad surface or near the specimen edge without the cladding layer, is rather surprising - shot peening usually does result in surface hardening, particularly in steels [14].

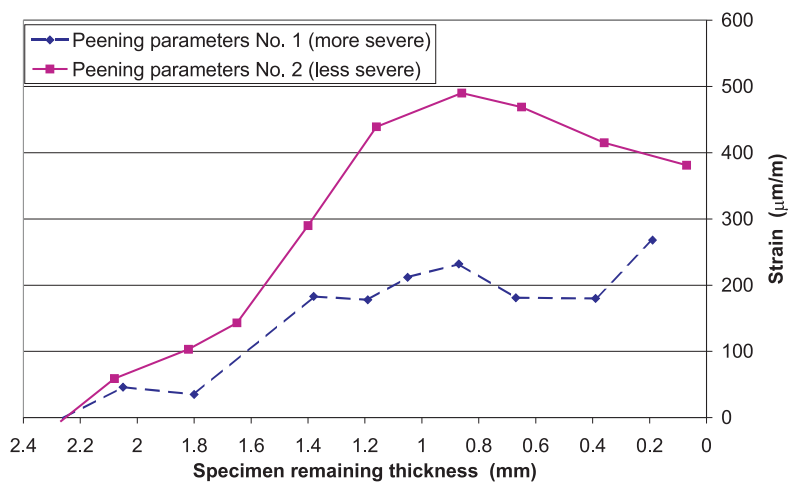

Fig. 7 Strain values recorded as a dependence on specimen remaining thickness during grinding material off

The diagram of strain values recorded as a dependence on the specimen remaining thickness, when the material was ground off from the surface opposite to that with the strain gauge, is in Fig. 7. One could expect that the more severe treatment will result in higher strain values. Some explanation could be found in the fact that the measurement was not carried out at the same surface point - the position of the strain gauge on the specimen peened with the more intensively was outside the centre as mentioned above (Fig. 2).

As regards the strain values after the material relaxation (stress release) at the final step (residual thickness $0.15 \mathrm{~mm}$ ) namely 270 and $380 \mu \mathrm{m} / \mathrm{m}$, respectively, considering the E-modulus $72 \mathrm{GPa}$, the strain values would correspond to compressive stresses of 19 and $27 \mathrm{MPa}$, respectively, if the simplified conditions are accepted. It is not too much, but on the other hand, considering the fact that the applied maximum stress of $160 \mathrm{MPa}$ was quite close to the material fatigue limit [15], even small changes of surfaces residual stresses to negative values resulting eventually in a reduction of the overall maximum stress can affect fatigue life quite significantly. It should be mentioned once more that the quantitative assessment can be considered just as informative.

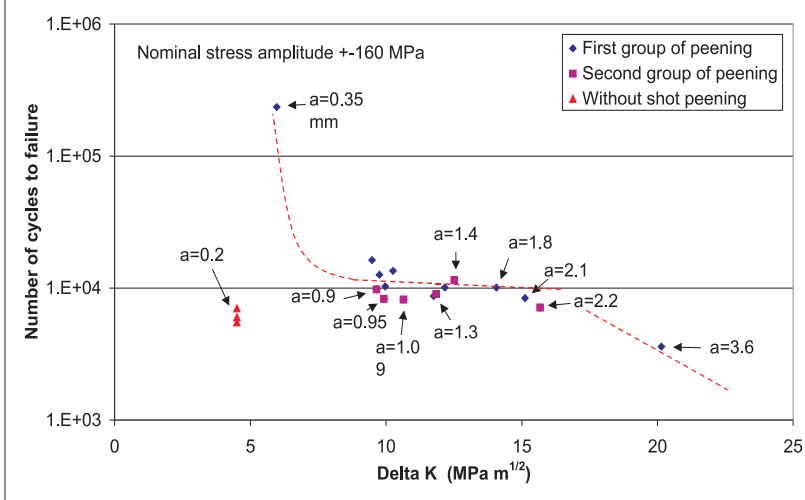

Fig. 8 Residual fatigue life as a dependence on stress intensity factor range and crack length

Survey of residual fatigue life of the pre-cracked specimens after application of shot peening in comparison with untreated specimens is shown as a dependence on stress intensity factor range $\Delta K$ in Fig. 8. The K-factor was calculated disregarding the short crack effects, i.e. the standard formula for long cracks was used. As regards the fatigue life of specimens without shot peening, tested to failure at the same stress amplitude, the total life was much longer, not only between 5000 and 8000 cycles as shown in Fig. 8. The experimental points of these three specimens namely correspond just to the crack growth stage starting with the length $0.2 \mathrm{~mm}$, i.e. $\Delta K=4.5 \mathrm{MPa} \mathrm{m}^{1 / 2}$, which could be reliably detected and measured by the DCPD method.

It follows from Fig. 8 that the retardation effect resulting from shot peening was quite significant. In the region of crack length between 1 and $2 \mathrm{~mm}, \Delta \mathrm{K}$ between 10 and $15 \mathrm{MPa} \mathrm{m}^{1 / 2}$, the residual life is always longer than that of the unpeened specimens with the crack length just $0.2 \mathrm{~mm}$. The slightly higher retardation effect of the more severe shot peening (the first group in Fig. 8) particularly on short crack of length less than $1.5 \mathrm{~mm}$ can be attributed to the more homogeneous distribution of the compressive residual stresses indicated in Fig. 7.

Similar effects of strong retardation of short fatigue cracks in compressive residual stress fields were described e.g. in [16 and 17]. In [17], shot peened $\mathrm{Al} 7475$ alloy under fatigue loading was studied. Retardation of physically short fatigue cracks in the field of compressive residual stresses was also described in [18], though the cracks initiated by fretting fatigue in that case. 
There is another interesting effect in Fig. 8, namely the plateau between $\Delta K 10$ and $15 \mathrm{MPa} \mathrm{m}^{1 / 2}$ (crack length between 0.8 and $2.0 \mathrm{~mm}$ ), where the residual fatigue life is almost constant. The detailed measurement of actual crack growth rate from its beginning in the field of residual stresses indicated some reasons for this phenomenon - Fig. 9 .

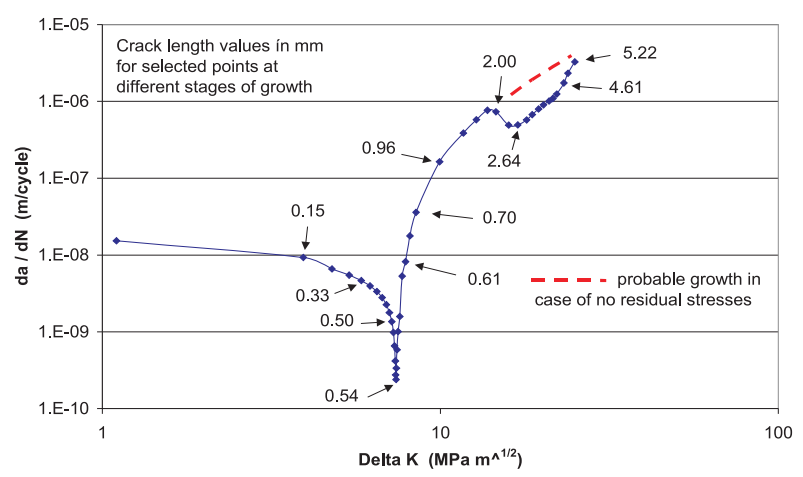

Fig. 9 Short crack growth rate in the field of residual stresses

The measurement in Fig. 9 was performed on a specimen peened with the less severe parameters. In spite of that the modified DCPD method, suitable for short cracks was used to record the short crack growth [10-13, 19], DCPD values were recorded continuously to eliminate scatter and make the measurement even more precise. There was no artificial initiator at the edge, the crack initiated spontaneously. The growth process in Fig. 9 can be divided into four stages: (i) initiation and growth of physically short crack, ending at the crack length approximately $0.6-0.7 \mathrm{~mm}$, (ii) relatively short period of a more or less regular growth up to the length $1.9-2.0 \mathrm{~mm}$, (iii) retardation period ending at the length $4.5 \mathrm{~mm}$ and (iv) final acceleration approaching the regular long crack growth again. It can be anticipated that the first progressive retardation with the minimum growth rate at the length $0.54 \mathrm{~mm}(\Delta K=7.4$ $\mathrm{MPa} \mathrm{m}{ }^{1 / 2}$ ) is caused more by the short crack phenomenon than by compressive residual stresses - it corresponds to the transient period between crystallographic and $K_{I}$ mode of growth. This transient period ends at the crack length approximately $0.7 \mathrm{~mm}(\Delta K=8.5$ $\mathrm{MPa} \mathrm{m}^{1 / 2}$ ). The second significant retardation is likely caused by compressive residual stresses, which are probably greatest in the shot peened area, near the boundary between the peened and unpeened areas. The shift of effective $\Delta K$ value in the diagram corresponds to $30 \%$. Considering the stress range $\Delta \sigma=160 \mathrm{MPa}$ and load asymmetry $R=0$, the compressive residual stresses would correspond to - $50 \mathrm{MPa}$. It is about $65 \%$ more than the longitudinal residual stresses, which were actually measured. It is, however, likely that the point at the centre of the shot peened band, where the strain gauge was bonded (Fig. 1), is not exactly identical to the point of maximum residual stresses near the peened boundary line according to Fig. 9.

\section{Conclusions}

An experimental investigation of an effect of quite severe shot peening with two different groups of parameters on subsequent retardation and further growth of physically short fatigue cracks to failure in $2.4 \mathrm{~mm}$ thick aircraft V-95 Al-alloy sheets (a type of a 7075 alloy), clad with a 7072 Al-alloy (Al-Zn1) was carried out. The significant part of the work was a measurement of actual growth rates of a crack growing throughout the peened area from its beginning, from the length less than $0.2 \mathrm{~mm}$. The main conclusions can be summarised as follows:

- Physically short fatigue cracks of the length from $0.2 \mathrm{~mm}$ to more than $3 \mathrm{~mm}$, most of them between $0.8-1.5 \mathrm{~mm}$, were prepared under high cycle repeated fatigue loading (load asymmetry $R=0$ ) of the constant maximum stress $160 \mathrm{MPa}$. Crack growth after shot peening was measured and compared with crack growth in specimens without shot peening. Retardation of crack growth was significant particularly for cracks shorter than $2 \mathrm{~mm}$. Some minor differences between the two groups of shot peening parameters were ascertained.

- Metallographic analyses of surface and subsurface microstructure confirmed an extensive plastic deformation of the peened layer localised in the cladding layer. The bulk material microstructure remained undeformed. The basis microstructure was slightly deformed just in the area of the absence of the cladding layer.

- No surface and subsurface hardening was observed either in the cladding layer or basic material. The increase of residual fatigue life of specimens with preliminary cracks and total fatigue life of specimens without cracks was therefore attributed just to the compressive residual stresses.

- A simplified residual stress measurement indicated significant differences in the through thickness residual stress relief between specimens peened with the two different parameters. A presence of surface or subsurface compressive residual stresses was confirmed.

- There were two retardation periods in the short fatigue crack growth rate diagram, the first one caused probably mostly by the short crack phenomenon, the second one, when the crack front approached the boundary line between the shot peened and unpeened areas, probably by longitudinal compressive residual stresses.

\section{Acknowledgements}

The work was carried out under the support of Ministry of Education, Youth and Sports of Czech Republic, grant MSM 2579700001 


\section{References}

[1] VOORWALD. H. J. C., SILVA, M. P., COSTA, M. Y. P., CIOFFI, M. O. H.: Fatigue Fract. Eng. M., 32, 2009, 2,97

[2] CAMARGO, A., VOORWALD, H. J. C.: Fatigue Fract. Eng. M., 30, 2007, 11, 993

[3] RODOPOUlOS, C. A., CURTIS, S. A., DE LOS RIOS, E. R., SOLIS, R. J.: Int. J. Fatigue, 26, 2004, 8, 849

[4] HATAMLEH, O., LYONS, J., FORMAN, R.: Fatigue Fract. Eng. M., 30, 2007, 2, 115

[5] NOVY, F., CHALUPOVA, M., CINCALA, M., BOKUVKA, O.: Acta Mech. Slovaca, 11, 2007, 4, 189

[6] NOVY F., BOKUVKA, O., CHALUPOVA, M., VALOVICOVA, V.: Acta Mech. Slovaca, 12, 2008, 4-B, 209

[7] KUBEnA, I., KRUML, T., HUTAR, P., NAHLIK, L., SEITL, S., POLAK, J.: Fatigue Properties of Eurofer Steel Developed for Fusion Application. In: Proc. of the $18^{\text {th }}$ Int. Conf. on Metallurgy and Materials METAL 2009 - Symposium C, Tanger s.r.o. Ed., Ostrava, 2009, 125

[8] KARLASHOV, A. V., GAINUTDINOV, R. G., GOLUBNICHII, A.V.: Mater. Sci+, 11, 1976, 1, 100

[9] ZAKHAROV, E. D., PETROVA, A. A., ZHIKHAREV, YU. V., SAVElOVA, N. M.: Met. Sci. Heat. Treat+, 5, 1963, 12, 696

[10] CERNY, I.: Eng. Fract. Mech., 71, 2004, 4-6, 837

[11] CERNY, I.: Int. J. Pres. Ves. Pip., 78, 2001, 11-12, 893

[12] CERNY, I.: Procedia Engineering, 10, 2011, 3411

[13] CERNY, I., SIS, J., MIKULOVA, D.: Surf. Coat. Technol., 2012, doi:10.1016/ j.surfcoat.2012.06.008 (in press)

[14] AZAR, V., HASHEMI, B., YAZDI, M. R.: Surf. Coat. Technol., 204, 2010, 21-22, 3546

[15] ASM Aerospace Specification Metals Inc., Aluminum 7075-T73; 7075-T735x, http://asm.matweb.com/search/SpecificMaterial.asp?bassnum=MA7075T73

[16] MAJZOOBI, G. H., AHMADKHANI, A. R.: Surf. Coat. Technol., 205, 2010, 1, 102

[17] GAO, Y. K., WU, X. R.: Acta Mater., 59, 2011, 9, 3737

[18] LINHART, V., CERNY, I.: Eng. Fract. Mech., 78, 2011, 5, 731

[19] CERNY, I.: The Use of DCPD Method for Measurement of Growth of Physically Short Fatigue Cracks. In: Proc. of the $1^{\text {st }}$ Int. Conf. on Recent Trends in Structural Materials COMAT 2010, COMTES FHT a.s. Ed., Plzen, 25-26 November 2010, 242. 